\title{
GENÉTICA DE PEIXES NEOTROPICAIS. I. ASPECTOS DA CONSERVAÇÃO GENÉTICA DOS PEIXES NO PARQUE ESTADUAL DE VILA VELHA, PARANÁ, BRASIL
}

\section{NEOTROPICAL FISH GENETICS. I. ASPECTS OF GENETIC CONSERVATION OF FISH IN THE STATE PARK OF VILA VELHA, PARANÁ, BRAZIL}

\author{
Roberto Ferreira Artoni ${ }^{1 *}$ e Mara Cristina de Almeida Matiello ${ }^{1}$ \\ $1^{*}$ Autor para contato: Universidade Estadual de Ponta Grossa, Campus em Uvaranas, \\ Departamento de Biologia Estrutural, Molecular e Genética, 84030-900 Ponta Grossa, \\ PR, Brasil; fax: +55-42-220-3102; e-mail: rfartoni@uepg.br
}

Recebido para publicação em 20/07/2003

Aceito para publicação em 08/09/2003

\section{RESUMO}

Neste trabalho nós apresentamos uma abordagem inicial acerca da variabilidade genética de peixes do Parque Estadual de Vila Velha na região de Ponta Grossa, Paraná, sob a influência da bacia hidrográfica do alto rio Tibagi. Os primeiros resultados consistentes envolvendo análises de cariótipo, marcadores moleculares e morfológicos apontam para diferentes situações em relação ao estado de conservação genética das espécies de peixes naturais da região. Situações de risco são apontadas e discutidas para espécies endêmicas e migradoras ressaltando a necessidade da continuidade dos estudos para maiores conclusões acerca da história evolutiva das espécies locais e da preservação do seu patrimônio genético.

Palavras-chave: Peixes, Parque Estadual de Vila Velha, evolução cariotípica, marcadores moleculares, conservação

\begin{abstract}
In this work we presented an initial approach to the genetic variability of fish at the State Park of Vila Velha (Ponta Grossa region, Paraná, Brazil), under the influence of the upper Tibagi river hydrographic basin. The first solid results of karyotype analyses, molecular and morphological markers point to different situations concerning the genetic conservation of the fish species. We point out and discuss risk situations for endemic migratory species and emphasize the need of further studies to arrive at more precise conclusions about the evolutionary history and genetic preservation of local species.
\end{abstract}


Key words: Fish, State Park of Vila Velha, karyotype evolution, molecular markers, conservation

\section{Introdução}

Existem três razões para justificar a genética como uma das principais áreas da conservação biológica. Primeiramente, conforme o Teorema Fundamental da Seleção Natural, a taxa de mudanças evolutivas nas populações é proporcional ao conteúdo de diversidade avaliada. Assim sendo, quando a diversidade genética decresce em uma população, a taxa potencial de mudanças evolutivas, também se reduz. Essencialmente, a perda da diversidade genética reduz as futuras possibilidades evolutivas. Em segundo lugar, é um consenso entre os geneticistas de populações que a heterozigosidade, ou alta variabilidade genética intrapopulacional, está positivamente relacionada à adaptação. Finalmente, o pool gênico representa toda a informação genética disponível nos organismos vivos. Um organismo diplóide só pode apresentar dois genes alelos para um mesmo locus em seus dois cromossomos homólogos. Entretanto, na população podem estar representados os diferentes alelos para um mesmo locus, ou seja, toda variabilidade genética nela existente (Meffe e Carroll, 1994).

A conservação genética pode ser considerada sob dois aspectos: a conservação ex situ, ou seja, aquela que se ocupa de estratégias evasivas como a criopreservação (estocagem de células reprodutivas em nitrogênio líquido) e/ou preservação de DNA in vitro, sem levar em consideração o ambiente, e a conservação in situ, ou seja, aquela que se ocupa em manter a diversidade no seu local de origem. Os dois esforços têm suas justificativas e seus fins; contudo, nos deteremos em analisar aqui apenas dados relativos à segunda alternativa, no que se refere à conservação de espécies de peixes neotropicais.

Aspectos da conservação genética têm sido mais extensivamente apresentados para peixes da América do Norte, como no caso de peixes do deserto (Vrijenhoek et al., 1985, Meffe e Vrijenhoek, 1988) ou peixes de riachos (Vrijenhoek et al., 1987), permitindo analisar a estrutura de comunidades, sua ecologia evolutiva e, desta forma, fornecer subsídios para recomendar o manejo, e conseqüentemente, manter a variabilidade genética.

Com o avanço da genética molecular, nas últimas décadas, técnicas utilizando marcadores de DNA foram desenvolvidas permitindo, entre outros aspectos, calcular as distâncias genéticas entre populações e espécies e a heterozigosidade em demes específicos. Estes recursos também começaram a ser utilizados no estudo da variabilidade genética em peixes, especialmente em relação a aspectos evolutivos e sua relação com a biogeografia, a assim chamada filogeografia (Avise et al., 1987; Avise, 2000; Sivasundar et al., 2001, entre outros).

No Brasil, pouco tem sido feito no sentido de melhor utilizar os dados disponíveis sobre a variabilidade genética de populações naturais de peixes, especialmente em relação a citogenética (para revisão ver Almeida-Toledo, 1998), e sua relação com o ambiente visando à conservação deste importante recurso natural. Alguns marcadores de variabilidade genética em nível molecular tem sido empregados recentemente na conservação de peixes neotropicais (Sivasundar et al., 2001; Oliveira et al., 2002; Prioli et al., 2002; Wasko et al., 2002; Hatanaka e Galetti, 2003).

Estudos cariotípicos têm procurado revelar o nível de variabilidade cromossômica em peixes da região do baixo rio Tibagi, especialmente em relação a espécies da família de bagres e mandis neotropicais Pimelodidae (Dias e Giuliano-Caetano, 2003).

O presente estudo apresenta uma abordagem multidisciplinar, com o intuito de avaliar a variabilidade genética de peixes neotropicais na região do Parque Estadual de Vila Velha (PEVV), através de análises morfológicas, citogenéticas e de genética molecular, com vistas à evolução e conservação desses peixes. 


\section{Material e métodos}

\section{Local de Estudo}

O Parque Estadual de Vila Velha (PEVV) é uma unidade de conservação (UC) criada em 1953, pela lei estadual número 1.292. Possui uma área total de 3.122,11 hectares e está localizado no Estado do Paraná, na região dos Campos Gerais, no curso superior da bacia hidrográfica do rio Tibagi.

No PEVV existem formas raras de relevo em arenito, conhecidas por "furnas". A palavra "furna” significa gruta, caverna ou orifício crateriforme, constituída de blocos de rochas. Sua origem foi atribuída por Soares (1989), como resultante da ação do lençol freático em zonas de fraturamentos, gerando poços de desabamento. As furnas "comunicam-se” entre si através de pequenas fendas, à exceção da furna 3 que apresenta fundo seco, sem que haja uma passagem contínua definida (Rabello e

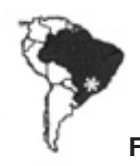

Furna 1 Furna 2 Furna 3 Furna 4 Lagoa Dourada

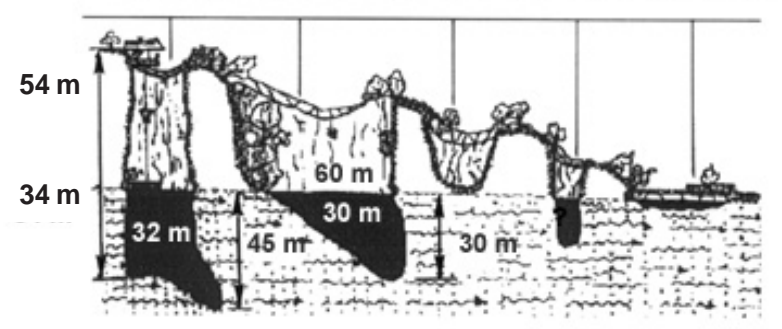

Figura 1- Perfil das Furnas no Parque Estadual de Vila Velha.

Soares, 1991). Sendo assim, as furnas constituem um ambiente restrito e peculiar dos pontos de vista geológico e biológico (Figura 1).

Todas as furnas deságuam, por via subterrânea, numa lagoa em forma de caldeirão, com um diâmetro de 200 metros aproximadamente, denominada Lagoa Dourada. Esta é circundada por árvores, entre as quais destacam-se araucárias e palmeiras, suas águas escoam constantemente no rio Guabiroba (Maak, 1956). Através do rio Guabiroba a lagoa tem ligação com o rio que dá nome à bacia hidrográfica do Tibagi. Grande variedade de peixes freqüentam a Lagoa Dourada, a qual constitui um refúgio para essas espécies, enquanto nas furnas ocorrem formas raras de lambaris do gênero Astyanax, pouco conhecidas e endêmicas (Artoni e Almeida, 2001).

\section{Métodos \\ Amostragem}

Espécimens representativos de diferentes espécies de peixes da região foram capturados vivos na micro bacia do alto rio Tibagi nos limites do Parque Estadual de Vila Velha (município de Ponta Grossa, Paraná) com o auxílio de diferentes materiais de pesca e transportados até o Laboratório de Citogenética e Evolução (M40), da Universidade Estadual de Ponta Grossa, onde foram processados segundo as metodologias abaixo indicadas. As localidades e espécies analisadas estão apresentadas na Tabela 1.

\section{Citogenética}

Os cromossomos mitóticos foram obtidos segundo Bertollo et al. (1978). A heterocromatina constitutiva foi evidenciada pela técnica de Sumner (1972). A detecção das regiões organizadoras de nucléolos foi obtida pela técnica de impregnação pelo nitrato de prata (Ag-RONs), descrita por Howell e Black (1980). A heterocromatina constitutiva foi detectada pelo método de Sumner (1972).

A organização do cariótipo dos peixes seguiu a ordenação dos cromossomos em ordem decrescente de tamanho e também agrupados por tipos morfológicos em classes distintas, sendo classificados pela relação de braços (RB), em metacêntricos $(\mathrm{RB}=1,00$ a 1,70$)$, submetacêntricos $(\mathrm{RB}=1,71$ a $3,00)$, subtelocêntricos $(\mathrm{RB}=3,01$ a 7,00$)$ e acrocêntricos (RB a partir de 7,01) (Levan et al., 1964).

\section{Marcadores Moleculares}

O DNA de fígado foi extraído seguindo o método Sambrook et al. (1989).

Para a análise de fragmentos de restrição do tipo RFLP foi efetuada a amplificação da região controle (D-loop) do DNA mitocondrial de Astyanax sp. em um termo-ciclador PTC-100 MJ 
Research, com os primers FTTF (5' GCC TAA GAG CAT CGG TCT TGT AA 3' e F12R (5’ GTC AGG ACC ATG CCT TTG TG 3’).

As digestões enzimáticas foram realizadas com: 2 ml de água mili Q, 0.5 ml da solução tampão da enzima diluída 1 vez, e $0.5 \mathrm{ml}$ da enzima testada (10 u/ml), $7 \mathrm{ml}$ de DNA amplificado na concentração de $400 \mathrm{ng}$, incubação a $37^{\circ} \mathrm{C}$ “overnight”. O DNA foi digerido em solução da enzima ClaI.

Os ensaios de RAPD/PCR foram feitos com o kit Ready-to-go (Pharmacia) seguindo as especificações do fabricante.

Os produtos de amplificação foram analisados em gel de agarose $2 \%$, corado com brometo de etídeo a $10 \mathrm{mg} / \mathrm{ml}$. A análise de imagens foi feita com o programa Kodak Electrophoresis Documentation and Analysis System (EDAS) 290.

\section{Resultados e discussão}

Entre os Characiformes ("a maioria dos peixes de escamas sul-americanos”), existem basicamente dois padrões de diversificação cromossômica. No primeiro, grupos como as famílias Erythrinidae (ex. Hoplias malabaricus; traíras) e Characidae (ex. Astyanax; lambaris), podem mostrar uma grande variabilidade interpopulacional quanto ao número e estrutura cromossômica, provavelmente em decorrência de um estilo de vida mais sedentário, propiciando tal diversificação entre populações isoladas. No segundo grupo, destacam-se as famílias com uma pequena variação numérica e estrutural, como ocorre em Anostomidae (ex. Leporinus; piau) e Prochilodontidae (ex. Prochilodus; curimba). Nesses grupos, a alta mobilidade e hábito migrador, pode contribuir para a maior homogeneização genética observada. Contudo, deve-se ressaltar que, mesmo nesses grupos com uma macroestrutura cariotípica mais conservada, a variabilidade genética se faz presente em nível de segmentos cromossômicos ou de DNA.

Hoplias cf. malabaricus, da Lagoa Dourada, apresenta $2 \mathrm{n}=42$ cromossomos em ambos os sexos (Tabela 1), assim como observado em traíras de outras bacias hidrográficas, com cabeceiras no Estado do Paraná, próximas a Ponta Grossa, indicando uma possível unidade taxonômica para estes peixes nessa região (Vicari, 2003). Bandas de RAPD-PCR tem auxiliado na investigação da filogeografia de Hoplias malabaricus da região sul do Brasil (Dergam et al., 1998; 2002). Estes estudos corroboram a forte relação de parentesco entre as diferentes populações analisadas, contudo, algumas diferenças inter e intrapopulacionais verificadas em Hoplias malabaricus, assim como sua dispersão na região pode ser mais bem entendida quando se analisa os processos geomorfológicos de formação de grandes bacias hidrográficas como as dos rios Iguaçu, Tibagi e Ribeira (Vicari et al., em preparação).

Prochilodus cf. lineatus se caracteriza por apresentar uma variação no número cromossômico, de $2 n=54$ a 57, devido à presença de cromossomos supranumerários (cromossomos B), os quais variam intraindividualmente na população da Lagoa Dourada (Tabela I). Estes cromossomos são consideravelmente menores que os demais cromossomos do complemento cariotípico (cromossomos A) e totalmente heterocromáticos. Muito pouco é ainda conhecido sobre a importância ou papel desses cromossomos nos organismos e populações portadores dos mesmos. Assim, a presença de cromos-somos supranumerários em peixes migradores, como Prochilodus, merece atenção especial quanto a uma possível relação com a estrutura populacional desses peixes e com o ambiente, mesmo porque são poucos os locais de refúgio, ainda intactos no rio Tibagi, que permitem a reprodução e o crescimento de peixes. Hatanaka e Galetti (2003), estudando populações de Prochilodus margravii em relação à freqüência de fragmentos polimórficos de DNA (RAPD) amplificados pela técnica da PCR (Reação em Cadeia da Polimerase), verificaram uma estruturação populacional para estes peixes na região da represa de Três Marias, no rio São Francisco (MG).

A manutenção de uma grande variabilidade genética em espécies migradoras de peixes é atribuída a um suposto fluxo gênico intenso entre populações distintas. Contudo a indicação de estruturação populacional aponta para uma maior endogamia e, neste sentido, estas informações tornam-se relevantes para a manutenção de estoques populacionais e da própria conservação das espécies.

A subfamília Salmininae, representada por 

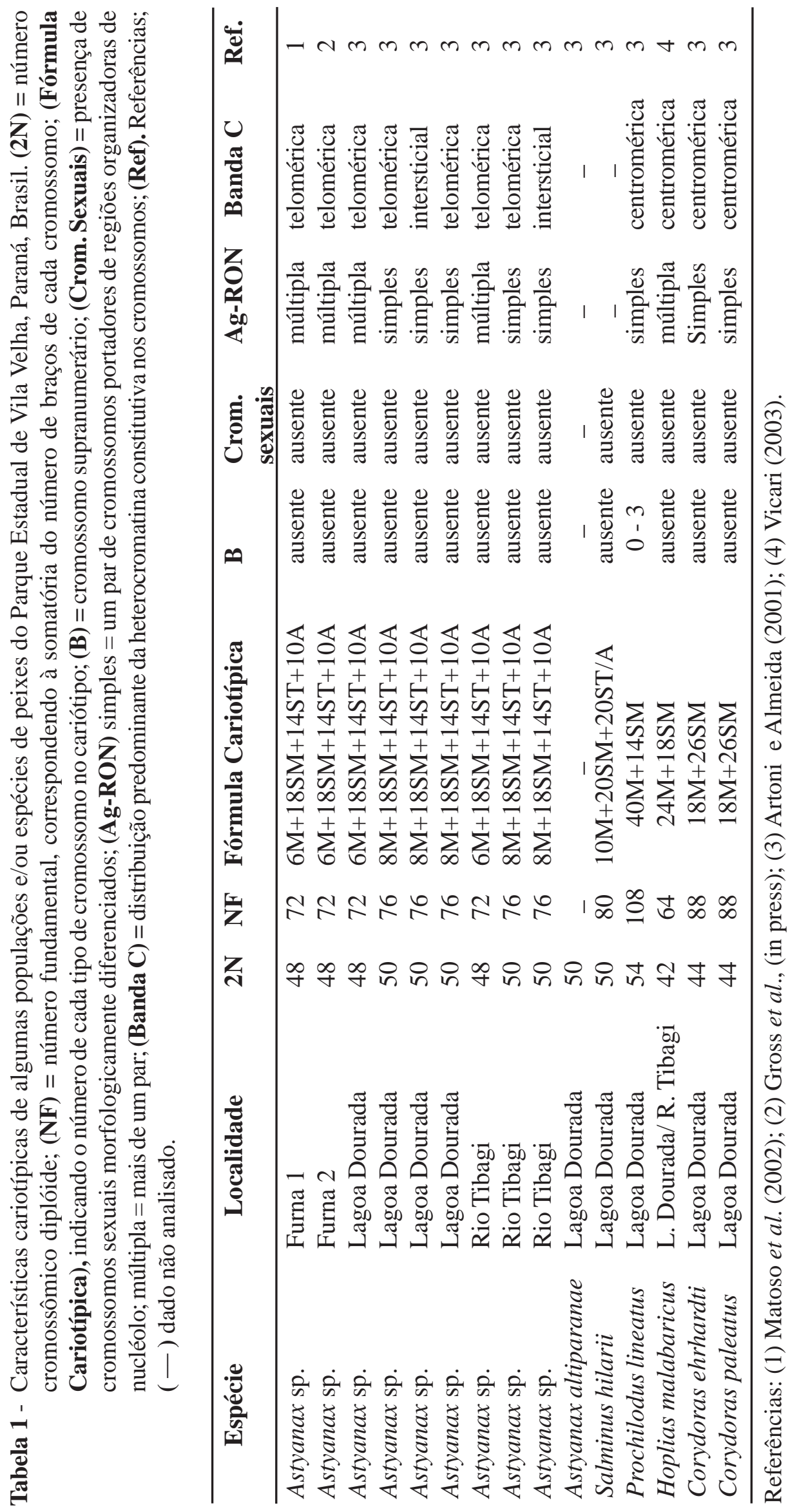

Publ. UEPG Ci. Biol. Saúde, Ponta Grossa, 9 (2): 7-15, jun. 2003 
Salminus hilarii (tabarana), outro peixe de interesse comercial como os corimbas, apresenta uma constância na macroestrutura cariotípica ( $2 n=50$ cromossomos, para machos e fêmeas, Tabela1), compatível com análises realizadas nesta espécie por outros autores, em distintas bacias hidrográficas (Souza, 2001). Estas observações evidenciam o alto grau de conservação do cariótipo dessa espécie, também migradora, provavelmente sujeita a um fluxo gênico mais acentuado. O rio Tibagi não apresenta grandes barragens para a geração de energia elétrica como acontece com o rio Iguaçu e esta é uma das condições que ainda permite a sobrevivência de peixes migradores como o corimba (Prochilodus) e a tabarana (Salminus).

Duas espécies de pequenos siluriformes do gênero Corydoras, C. paleatus e C. ehrhardti, ocorrem em simpatria e sintopia na Lagoa Dourada e na região de abrangência do município de Ponta Grossa (Paraná). Outros estudos têm demonstrado grande similaridade na macroestrutura cariotípica entre estas espécies, ambas com $2 \mathrm{n}=44$ cromossomos, mesmo quando coletadas em localidades distintas (Oliveira et al., 1993). Na Lagoa Dourada, essas espécies também compartilham o mesmo número diplóide ( $2 \mathrm{n}=44)$, mostrando, contudo uma variação na localização das Ag-RONs e no número de cromossomos portadores dessas regiões. O aprofundamento das análises citogenéticas, em nível populacional, mostrará se esta variação reflete um estado polimórfico do caráter ou se as RONs seriam caracteres válidos para a caracterização dessas duas entidades taxonômicas nesta zona de simpatria.

Em Astyanax sp., um tipo de lambari só encontrado nas furnas e entorno do Parque Estadual de Vila Velha, observou-se um número cromossômico diplóide $2 \mathrm{n}=48$ (Matoso et al., 2002), enquanto que no alto rio Tibagi e na Lagoa Dourada é possível verificar a ocorrência simpátrica de duas formas, uma semelhante aos lambaris das furnas, ou seja, com o cariótipo $2 \mathrm{n}=48$ (tipo furnas) outra com $2 n=50$ (tipo alto Tibagi). Na forma $2 n=50$ podem ser identificados dois citótipos, um com maior quantidade de heterocromatina constitutiva, principalmente telomérica no braço longo dos cromossomos acrocêntricos e o outro com pouca heterocromatina constitutiva, intersticial, localizada em poucos cromossomos do complemento (Tabela 1). Esta questão está sendo submetida a estudos complementares, mas aponta para um possível complexo de espécies relacionado aos Astyanax na região do Parque de Vila Velha.

Estas observações não só reafirmam a complexa estrutura cariotípica verificada em diferentes populações do gênero Astyanax, como também evidenciam a estrutura cariotípica diferenciada entre prováveis populações isoladas, reforçando a hipótese de endemismo e a fixação de rearranjos cromossômicos que levaram à atual constituição cariotípica de Astyanax sp. Os lambaris encontrados nas furnas, muito particularmente devem estar isentos de predação natural e competição por alimento, fatores estes que podem levar a um aumento efetivo da população.

A ausência de fluxo gênico pode ser um possível fator que propiciou as diferenciações em nível de bandamentos cromossômicos e da macroestrutura cariotípica entre as populações de lambaris, alertando para os efeitos de endogamia que podem baixar a variabilidade genética e fragiliza às populações em relação à extinção, especialmente com respeito a efeitos antrópicos. Esta hipótese está sendo também avaliada por marcadores de DNA genômico e mitocondrial (Figura 2) e morfológicos, do tipo assimetria flutuante, com resultados preliminares que indicam tratar-se de especiação recente com diminuição da heterozigose (Matoso et al., 2002; Gross et al., enviado para publicação).

Nas populações humanas, já são bem conhecidas as conseqüências deletérias da endogamia, que podem incluir uma tendência mais elevada de mortalidade, retardamento mental, albinismo e outras anormalidades físicas. É possível que esta possa ser também a causa do grande número de indivíduos ( $\pm 50 \%)$ com alteração da coluna vertebral, verificados entre os peixes coletados na Furna 2 (Figura 3). Os efeitos de diminuição da variabilidade genética em populações endogâmicas é ainda maior quando consideramos que poucos indivíduos podem fundar uma nova população (Efeito do Fundador). Assim, cabe questionar se os lambaris das furnas mantém sua variabilidade genética e como isto ocorre, ou se as populações estão em depressão. Mesmo aparentando ser um modelo de evolução recen- 

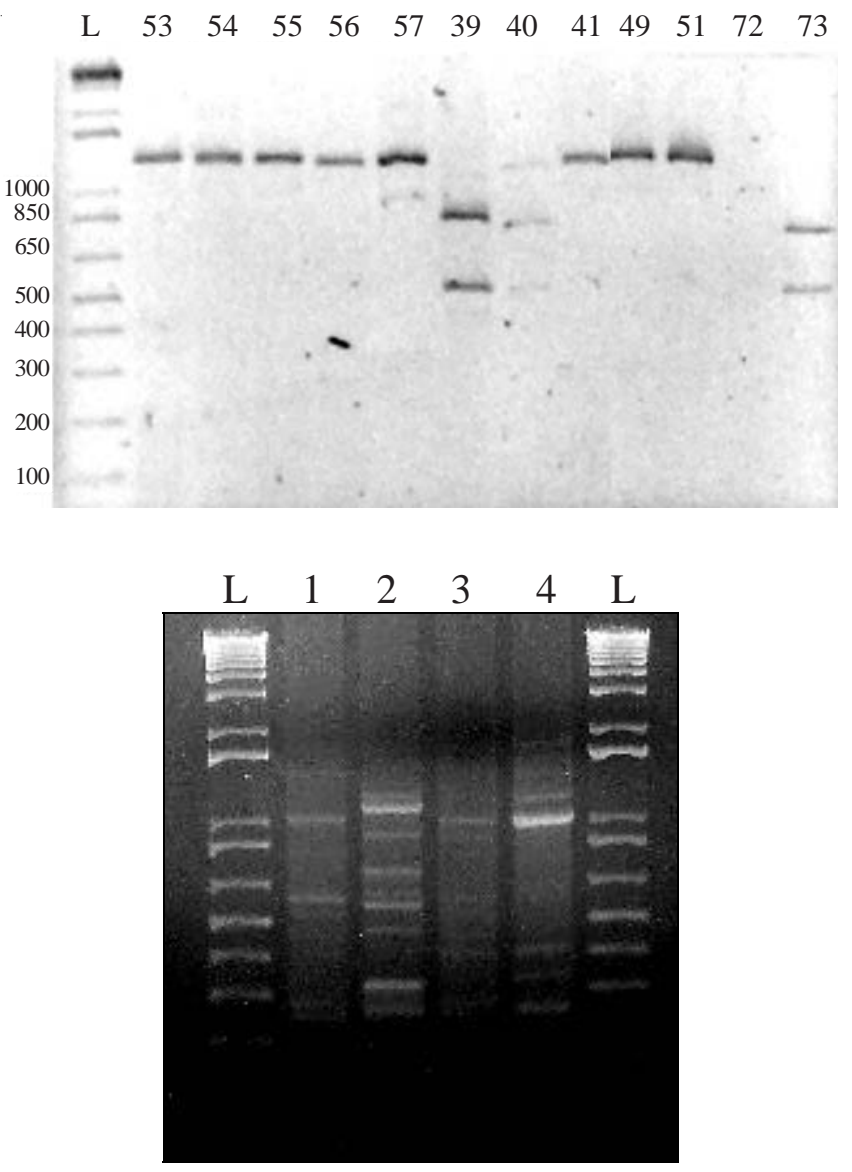

Figura 2 - Acima, gel de RFLP mostrando digestão enzimática do DNA mitocondrial de Astyanax sp. com ClaI, em indivíduos da Furna 1 (53 - 57) e rio Tibagi (39 - 73). Abaixo, RAPD/PCR evidenciando padrões de bandas diferenciados entre as populações de Astyanax sp. do PEVV: rio Tibagi (1 2), Lagoa Dourada (3) e Furna 2 (4). L = marcador de peso molecular.

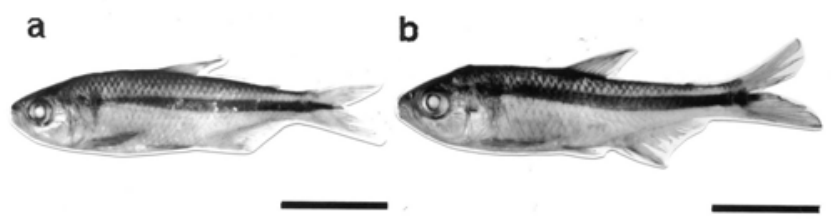

Figura 3 - Astyanax sp. da Furna 2 do PEVV. Em (a) tipo morfológico padrão e em (b) exemplar com alteração na coluna vertebral. A barra representa $2 \mathrm{~cm}$.

te, como estas populações se mantém estruturadas em termos de número efetivo de indivíduos? Essas são questões ainda em aberto.
Em conclusão, o inventário de espécies residentes e migradoras, assim como a caracterização genética das populações naturais, somados à manutenção dos diferentes ambientes num ecossistema, são de suma importância para a preservação da diversidade. Neste contexto, as Unidades de Conservação (UC’s), como o PEVV, assumem um papel fundamental, pois apresentam locais que permitem a reprodução e sobrevivência das espécies, como é o caso das Lagoa Dourada e Tarumã. Ambientes de refúgio facilitam a manutenção de estoques populacionais endêmicos e/ou mais vágeis, ou seja, peixes que se deslocam com maior eficiência nos cursos d'água, como as espécies migradoras, representando um papel de extrema importância na recomposição e manutenção da diversidade. Os rios, desta forma, funcionariam como corredores de preservação, e as UC's como fragmentos estoques de variabilidade (Artoni e Almeida, 2001).

\section{Agradecimentos}

Os autores são gratos aos Doutores Luis A. C. Bertollo, Orlando Moreira-Filho e Pedro M. Galetti Júnior do laboratório de Genética de Peixes (Universidade Federal de São Carlos) pelo apoio e cooperação no desenvolvimento do presente trabalho. Ao IAP (Instituto Ambiental do Paraná), IBAMA (Instituto Brasileiro do Meio Ambiente) e Paranaturismo por autorizarem a captura de peixes, especialmente no Parque Estadual de Vila Velha e ao $2^{\circ}$ Grupamento de Bombeiros de Ponta Grossa pelo apoio constante nas coletas de campo.

\section{REFERÊNCIAS}

1 ALMEIDA-TOLEDO, L.F. Cytogenetic markers in neotropical freshwater fishes. In: MALABARBA, L.R.; REIS, R.E.; VARI, R.P.; LUCENA, Z.M.; LUCENA, C.A.S. Phylogeny and classification of neotropical fishes, EDIPUCRS. Porto Alegre, 1998. p. 583-588.

2 ARTONI, R.F.; ALMEIDA, M.C. A singular diversidade dos peixes dos Campos Gerais: uma visão genética para abordagem conservacionista da região. In: DITZEL, C.H.M.; SAHR, C.L.L. Ponta Grossa e os Campos Gerais: estudos de geografia e história regional, Editora UEPG. Ponta Grossa. 2001. p. 505-518. 
3 AVISE, J.C. Phylogeography. The history and formation of species. Harvard University Press, Cambridge, Massachusetts, 2000. 447 p.

4 AVISE, J.C.; ARNOLD, J.; BALL, R.M.; BERMINGHAM, E.; LAMB, T.; NEIGEL, J.E.; REEB, C.A.; SAUNDERS, N.C. Intraespecific phylogeography: the mitochondrial DNA bridge between population genetics and systematics. Annual Review of Ecology and Systematics, v.18, p.489-522, 1987.

5 BERTOLLO, L.A.C.; TAKAHASHI, C.S.; MOREIRAFILHO, O. Cytotaxonomic considerations on Hoplias lacerdae (Pisces, Erythrinidae). Brazilian Journal of Genetics, v.2, n.1, p.17-37, 1978.

6 DERGAM, J.; SUZUKI, H.I.; SHIBATTA, O.A.; DUBOC, L.F.; JÚLIO Jr., H.F.; GIULIANO-CAETANO, L.; BLACK IV, W.C. Molecular biogeography of the Neotropical fish Hoplias malabaricus (Erythrinidae: Characiformes) in the Iguaçu, Tibagi, and Paraná rivers. Genetics and Molecular Biology, v.21, p.493-496, 1998.

7 DERGAM, J.; PAIVA, S.R.; SCHAEFFER, C.E.; GODINHO, A.L.; VIEIRA, F. Phylogeography and RAPDPCR variation in Hoplias malabaricus (Bloch, 1794) (Pisces, teleostei) in southeastern Brazil. Genetics and Molecular Biology, v.25, p.379-387, 2002.

8 DIAS, A.L.; GIULIANO-CAETANO, L. Citogenética de alguns grupos de peixes bacia do rio Tibagi. In: MEDRI, E.M.; BIANCHINI, E.; SHIBATTA, O.A.; PIMENTA, J.A. A bacia do rio Tibagi. Universidade Estadual de Londrina, Londrina, 2003. p. 473-529.

9 HATANAKA, T.; GALETTI Jr., P.M. RAPD markers indicate occurrence of structured populations in a migratory freshwater fish species. Genetics and Molecular Biology, v.26, p.19-25, 2003.

10 HOWELL, W.M.; BLACK, D.A. Controlled silver staining of nucleolus organizer regions with a protective colloidal developer: a 1-step method. Experimentia, v. 36, p. 1014-1915, 1980.

11 LEVAN, A.; FREDGA, K.; SANDBERG, A.A. Nomenclature for centromeric position on chromosomes. Hereditas, v. 52, p. 201-220, 1964.

12 MAAK, R. Fenômenos carstiformes de natureza climática e estrutural nas regiões de arenitos do estado do Paraná. Arquivos de Biologia e Tecnologia. Curitiba, v.11, p.151162, 1956.

13 MATOSO, D. A.; VICARI, M. R.; ALMEIDA, M. C.; SHIBATTA, O. A.; MOREIRA-FILHO, O.; BERTOLLO, L. A. C.; ARTONI, R. F. Karyotypic studies in the characidae fish, genus Astyanax. an endemic and highly isolated population of Astyanax sp. Cytologia, v.67, p.123-128, 2002.

14 MEFFE, G.K.; CARROLL, R. Genetics: Conservation of diversity within species, In: MEFFE, G.K.; CARROLL,
R. Principles of conservation biology. Sinauer Associates editors. Sunderland, MA, 1994. p.143-178.

15 MEFFE, G.K.; VRIJENHOEK, R.C. Conservation genetics in the management of desert fishes. Conservation Biology, v.2, n.2, p.1-13, 1988.

16 OLIVEIRA, C.; ALMEIDA-TOLEDO, L.F.; MORI, L.; TOLEDO-FILHO, S. Cytogenetic and DNA content studies of armoured catfishes of the genus Corydoras (Pisces, Characidae). Brazilian Journal of Genetics, v.16, n.3, p. 617-629, 1993.

17 OLIVEIRA, A. V.; PRIOLI, A. J.; PRIOLI, S. M. A. P.; PAVANELLI, C. S.; JÚLIO JR, H. F.; PANARARI, R. S. Diversity and genetic distance in populations of Steindachnerina in the upper Paraná river floodplain. Genetica, v.115, p.259-267, 2002.

18 PRIOLI, A. J.; SEKINE, E. S.; JÚLIO JR, H. F.; PRIOLI, S. M. A. P. Genetic diversity between populations of Pseudoplatystoma corruscans (Pisces - Siluriformes) isolated by Guaíra Falls of the Paraná River. Acta Scientiarum, v.24, n.2, p.507-512, 2002.

19 RABELLO, J.; SOARES, C.R. Nota sobre a origem geomorfológica e os parâmetros fisico-químicos e biológicos da coluna d'agua da furna no. 1 - Parque Estadual de Vila Velha (Estado do Paraná). XXI Congresso Brasileiro de Espeleologia. Curitiba (PR), 1991. (Suplemento).

20 SAMBROOK, L.B.; FRITSCH, E.F.; MANIATIS, T. Molecular cloning: a laboratory manual. Cold Spring Harbor Laboratory Press, $2^{\text {nd }}$ Edição, Cold Spring Harbor, NY, 1989.

21 SIVASUNDAR, A.; BERMINGHAM, E.; ORTÍ, G. Population structure and biogeography of migratory freshwater fishes (Prochilodus: Characiformes) in major South American rivers. Molecular Ecology, v. 10, p.407417, 2001.

22 SOARES, O. Furnas nos Campos Gerais, Paraná. Scientia et Labor, Editora da UFPR, Curitiba, 1989. 82 p.

23 SOUZA, I. rDNAs nucleares e bandamentos cromossômicos nos caracídeos Salmininae e Astyanax scabripinnis (Pisces, Characiformes). São Carlos, 2001. (Doutorado em Genética e Evolução) - Universidade Federal de São Carlos.

24 SUMNER, A.T. A simple technique for demonstrating centromeric heterochromatin. Experiment Cell Research, v. 75, p. 304-306, 1972.

25 VICARI, M.R. Citogenética comparativa de Hoplias malabaricus (Pisces, Erythrinidae). Estudos em região divisora de águas para as bacias dos rios Tibagi, Iguaçu, Ivaí e Ribeira (Ponta Grossa,PR). São Carlos, 2003. (Mestrado em Genética e Evolução) - Universidade Federal de São Carlos. 
26 VRIJENHOEK, R.C.; DOUGLAS, M.E.; MEFFE, G.K. Conservation genetics of endangered fish populations in Arizona. Science, v. 229, p.400-402, 1985.

27 VRIJENHOEK, R.C.; MARTEINSDOTTIR, G.; SCHENCK, R. Genotypic and phenotypic aspects of niche diversification in fishes. In: MATTHEWS, W.J.; HEINS, D.C. Evolutionary and community ecology of North American stream fishes. University of Oklahoma Press. Norman, 1987. p. 245-250.

28 WASKO, A.P.; GALETTI Jr. RAPD analysis in the Neotropical fish Brycon lundii: genetic diversity and its implications for the conservation of the species. Hydrobiologia, v.474, p.131-137, 2002. 